\title{
Summer drought and canopy opening increase the strength of the oak seedlings-shrub spatial association
}

\author{
Hassan Muhamed • Jean-Paul Maalouf • Richard Michalet
}

Received: 23 July 2012 / Accepted: 15 January 2013 /Published online: 7 February 2013

(C) INRA and Springer-Verlag France 2013

\begin{abstract}
- Context The knowledge of how shrub-seedling interactions vary with summer drought, canopy opening, and tree species is crucial for adapting forest management to climate change.

- Aims The aim of this study was to assess variation in shrub-oak recruitment associations along a south-north drought climate gradient and between two levels of canopy cover in coastal dune forest communities in a climate change-adapted forest management perspective.

- Material and methods Mapped data of associational patterns of seedlings of three oak species with interspecific pooled shrubs were analyzed using a bivariate pair correlation function in $10(0.315 \mathrm{ha})$ regeneration plots located in forest and recent gap sites along the climate gradient. An index of association strength was calculated in each plot and plotted against a summer moisture index.

- Results The association strength increased with increasing summer drought from wet south to dry north and from closed forests to gaps.

- Conclusion Consistent with facilitation theory, our results suggest that climate change may shift associational patterns in coastal dune forest communities towards more positive
\end{abstract}

Handling Editor: Douglass Jacobs

H. Muhamed $(\varangle) \cdot$ J.-P. Maalouf

University of Bordeaux, U.M.R. INRA 1202 BIOGECO,

Avenue des Facultés,

33405 Talence cedex, France

e-mail: hassan.muhamed@uod.ac

J.-P. Maalouf

e-mail: jeanpaul.maalouf@gmail.com

R. Michalet

University of Bordeaux, U.M.R. CNRS 5805 EPOC,

Avenue des Facultés,

33405 Talence cedex, France

e-mail: r.michalet@ecologie.u-bordeaux1.fr associations, in particular in canopy gaps. In a perspective of climate change, foresters may need to conserve understory shrubs in gaps in order to promote oak species regeneration.

Keywords Facilitation $\cdot$ Spatial association $\cdot$ Point pattern analysis $\cdot$ Stress gradient hypothesis

\section{Introduction}

The threat of climate change is now recognized as an imminent issue in forestry and incorporating adaptation to climate change into forest management is crucial for the long-term sustainability of forest ecosystem services and diversity (Millar et al. 2007). Several options for climate change adaptation have been explored, such as the control of climatically unfavored species, provenance testing, assisted migration, insect and disease control, or modifying the components of timber harvesting (Steenberg et al. 2011). Another aspect of climate change-adapted forest management which has been rarely addressed is the adaptation of sylvicultural techniques to changes in interactions between tree regeneration and understory species due to climate change (Fotelli et al. 2001; Saccone et al. 2009), although a number of studies have shown that forest understory composition is currently changing with climate change (i.e., Mendoza et al. 2009; Suarez and Kitzberger 2008).

Interactions between understory species and tree regeneration are known to be crucial in forest management but most studies have rather emphasized negative effects of understory species (often called forest weeds) for both productivity and regeneration success (Balandier et al. 2006; Nambiar and Sands 1993). However, positive effects of woody or herbaceous species on tree seedlings or saplings are increasingly shown to occur in forest or woodland communities, in particular in severe environmental conditions 
(Callaway et al. 1996; Rodriguez-Garcia et al. 2011a). The "nurse plant syndrome" mostly includes two different processes, either environmental stress mitigation (i.e., direct facilitation) or associational defences against grazers and browsers (Callaway 2007). In addition, positive effects may arise from indirect interactions among competitors (Callaway 2007; Saccone et al. 2010). For example, Rodriguez-Garcia et al. (2011b) found that overstory canopy of adult trees indirectly facilitated Pinus pinaster seedlings growth via suppression of the direct negative effects of Cistus ladanifer shrubs on $P$. pinaster seedlings. It is widely considered that interactions among species in plant communities including forests are dominantly negative when environmental conditions are favorable and turn to positive when environmental stress increases (i.e., stress gradient hypothesis (SGH; Bertness and Callaway 1994). This switch in interactions along stress gradients has been demonstrated in a number of experiments (see Callaway (2007) for a review) and facilitation is now considered as a useful tool for restoring woodlands in arid and semi-arid environments (Gomez-Aparicio 2009; Padilla and Pugnaire 2006).

Climate change is known to influence associations among species in plant communities (Brooker 2006; Saccone et al. 2009). Plant-plant interactions are strongly regulated by variation in climate conditions and climate change has been shown to also alter the direction and importance of interactions within plant communities (Brooker 2010). For example, Gomez-Aparicio et al. (2004) found in their meta-analysis conducted in the Sierra Nevada mountains in Spain that the net facilitative effect of nurse shrubs on seedling survival and growth increased at low altitudes and on sunny, drier slopes and decreased at high altitudes and on shady, wetter slopes. Additionally, they found that net facilitation increased in dry years as compared to wet ones

Thus, interactions between tree seedlings and understory species are expected to change in forest communities with climate change and these changes deserve to be considered in climate change-adapted forest management strategies. Based on the SGH, either competition or facilitation should increase if climate change decreases or increases climate stress, respectively (Brooker 2006). For example, in southern European latitudes where climate change is expected to increase summer drought (Intergovernmental Panel on Climate Change 2007), if the competitive effect of understory species on tree seedlings decreases, then there will be less need to control forest weeds for regeneration success. Furthermore, if facilitation increases, then foresters should rather conserve understory nurses to limit regeneration mortality due to drought.

However, it has been shown that competition may also remain important in water-stressed systems, in particular for tree seedlings competition with strong belowground competitors such as grasses (Fotelli et al. 2001). The role of facilitation in dry environments has been strongly debated but there is increasing evidence in recent studies that both competition and facilitation may occur in a same site depending on the species and the ecological factor involved in the interaction (Gomez-Aparicio 2009; Michalet 2007; Rodriguez-Garcia et al. 2011a; Saccone et al. 2009). Specifically, stress-intolerant species have been shown to be more sensitive to facilitative effects and stress-tolerant species to competitive effects (Liancourt et al. 2005). Furthermore, facilitation generally involves mostly nonresource factors (such as decrease in vapor pressure deficit and extreme temperatures), whereas competition rather involves resource factors (such as water or nutrient availability), as shown by Saccone et al. (2009).

Additionally, species have both negative and positive effects on each other that often depend on season or growth stage, which makes important to consider the net effect or the outcome of interactions (Callaway and Walker 1997) over a long time period, in particular in a forest regeneration perspective where regeneration success may only be evaluated after several years. A practical method to assess the long-term role of interactions for regeneration success is through the measurements of spatial associational patterns (Fajardo et al. 2006; Wiegand et al. 2006; Wiegand and Moloney 2004). For example, in a forest community, a high frequency of seedlings located close to nurse shrubs does not guarantee a lack of competition, but rather suggests that positive effects overwhelm negative ones on the long term (Padilla and Pugnaire 2006). Spatial patterns have recently received a strong renew of interest in ecology and spatial structure is considered to play an important role for species coexistence (McIntire and Fajardo 2009). This is in particular true for direct plant-plant interactions (Callaway and Walker 1997) and dispersal limitation (Nathan and MullerLandau 2000) and in general for all coexistence processes that display strong temporal and spatial variation. Additionally, in forest communities, there is a strong potential to study spatial patterns since there is a high availability of point pattern data (horizontal and vertical data arrangement) as compared to grasslands (Law et al. 2009; Wiegand and Moloney 2004).

The main goal of our study was to assess variation in the direction of tree seedlings-understory shrubs associational patterns with climate drought and canopy opening in a perspective of climate change-adapted management.

The coastal dune communities of the Aquitaine region (southwest France) are very good systems to address this issue since there is a $240-\mathrm{km}$ long strip of natural forest communities in similar sandy habitats but with varying climate drought, ranging from wet south toward dry north. Additionally, three oak species of contrasting functional strategies are located in the sandy coastal forest communities along a latitudinal gradient, the temperate deciduous oak Quercus robur throughout 
the gradient and two Mediterranean evergreen species, Quercus ilex in the dry north, and Quercus suber in the wet south. Thus, in this system, we may use space-for-time design to test for the effect of climate change (time effect) through studying spatial variation in ecological processes across sites differing in their current climate conditions (space effect) since there were few, if any, other confounding factors along the gradient, and in particular minimal soil variation and similar management regimes by the French National Forest Office.

We quantified associational patterns of the three oak seedlings with understory shrubs in forests and recent gaps across the climate gradient. Consistent with the SGH and with the results of studies on species-specific responses to interactions (i.e., Gomez-Aparicio 2009; Liancourt et al. 2005), we make the following predictions:

1. Understory shrub-oak seedling associational patterns should shift from negative to positive with increasing summer drought along the south-north climate gradient.

2. The removal of the forest canopy should increase positive associations between understory shrubs and oak seedlings due to increasing drought stress.

3. Association patterns may be species specific (i.e., vary depending of the oak species) with drought-tolerant species more negatively associated with understory shrubs than drought-intolerant species.

\section{Materials and methods}

\subsection{Sites, study species, and forest canopy treatments}

The study was conducted in the coastal dunes forests of the Aquitaine region (southwestern France) stretching along the Atlantic Ocean from the Gironde estuary in the north $\left(45^{\circ}\right.$ $32^{\prime} \mathrm{N}, 1^{\circ} 05^{\prime} \mathrm{W}$ ) to the mouth of the Adour River in the south $\left(43^{\circ} 41^{\prime} \mathrm{N}, 1^{\circ} 25^{\prime} \mathrm{W}\right)$. All along the sand strip, there are two kinds of dunes occurring in the region: mobile dunes with herbaceous communities close to the shoreline, and inland fossile dunes with forest communities at 1-10 km distance from the shoreline. The climate is overall temperate oceanic with the rainiest period during winter, but mean annual precipitation decreases with increasing distance from the Pyrenees mountain range from $1,200 \mathrm{~mm}$ in the south to $750 \mathrm{~mm}$ in the north. Maximum temperatures also slightly decrease from 25.9 and $17.6{ }^{\circ} \mathrm{C}$ (summer and spring, respectively) in the south to 23.6 and $15.4{ }^{\circ} \mathrm{C}$ in the north (Meteo-France data 2007). Three oak species dominate the forest communities, $Q$. robur, $Q$. Suber, and $Q$. ilex. $Q$. robur is a common oak species in Europe, in particular in its northern and central parts where climate is temperate with no summer drought, whereas the two evergreen species are mostly found in the Mediterranean climatic area of
Southern Europe and North Africa. These two Mediterranean oaks may also occur within the warm temperate or submeditteranean parts of Southern Europe where there is no summer drought, but only on dry soils, like is the case in the coastal dunes of the Aquitaine region. Thus, there is a strong difference in drought-tolerance between the deciduous temperate $Q$. robur and the two evergreen Mediterranenan species (Ozenda 1985). However, there are also differences in drought- and cold-tolerance between $Q$. suber and Q. ilex (David et al. 2007), the former inhabiting warmer and wetter Mediterranean climates than the latter (Ozenda 1985; Michalet 1991). In the coastal dunes of the Aquitaine region, $Q$. suber is indeed mostly present in the south where the climate is wetter and milder, whereas $Q$. ilex is very abundant in the north where the climate is drier and less mild.

Five latitudinal positions were chosen along the southnorth gradient of decreasing rainfall to select our plots in this study (Table 1). At each latitudinal position, for the canopy treatment a forest and a gap plot was selected when available. However, in the north, there was only a forest plot in the northernmost site (Soulac) since we did not find a suitable gap. Additionally, only the gap of the second northernmost site (Hourtin) was analyzed here since the forest plot did not include the interspecific associations required in this study. Most plots were located in an east exposure, where remained the oldest oak forests, since foresters stopped logging oak forests only on this exposure at least 30 years ago. All forest sites $(\mathrm{F})$ were mature forests with at least $75 \%$ canopy closure by mixed oak tree overstory and all open plots $(\mathrm{G})$ were recent gaps created (3-5 years) by opening overstory canopy through seed tree cutting method. In each plot, a uniform and homogeneous permanent 0.315 ha $(21 \times 15 \mathrm{~m})$ plot was established in the middle part of a moderate to steep slope (between $15^{\circ}$ and $25^{\circ}$ slope). Because of topographic limitations, the Bisc. $2 \mathrm{G}$ plot was arranged as $9 \times 35 \mathrm{~m}$.

\section{Data collection and statistical analysis}

In September 2009, the locations of oak species and shrub neighbors growing in each of the 10 plots were recorded (Table 1). Each plot was divided into 35 quadrats of $9 \mathrm{~m}^{2}$ using rubber tapes, and each quadrat was exhaustively surveyed. Individuals were classified in two categories: (1) seedlings (height, $<25 \mathrm{~cm}$ ), (2) shrubs (height, $>50 \mathrm{~cm}$; diameter at breast height (DBH), $<4 \mathrm{~cm}$ ). Because the minimum number of stems required to run the point pattern analyses $(n=30$; Meyer et al. 2008) was not found for sapling (height between 25 and $50 \mathrm{~cm}$ ) and adult tree (DBH, $\geq 4 \mathrm{~cm}$ ) categories in all plots, saplings, and seedlings of each oak species were pooled into one category (oak 
Table 1 Main characteristics of the study plots

\begin{tabular}{|c|c|c|c|c|c|c|}
\hline Study plot & $\begin{array}{l}\text { Canopy } \\
\text { treatment }\end{array}$ & Coordinates & $\begin{array}{l}\text { Distance to the } \\
\text { northermost }(\mathrm{km})\end{array}$ & Aspect & $\begin{array}{l}\text { Target oak } \\
\text { species }\end{array}$ & Main shrub species \\
\hline Soulac (So.) & Forest & $45^{\circ} 32^{\prime} \mathrm{N}, 1^{\circ} 05^{\prime} \mathrm{W}$ & 0 & $\mathrm{E}$ & Q. robur, Q. ilex & Arbutus unedo, Ruscus aculeatus, Q. ilex \\
\hline \multirow[t]{2}{*}{ Hourtin (Ho.) } & Forest & $45^{\circ} 11^{\prime} \mathrm{N}, 1^{\circ} 07^{\prime} \mathrm{W}$ & 76 & $\mathrm{E}$ & Q. robur, Q. ilex & Q. ilex \\
\hline & Gap & $45^{\circ} 09^{\prime} \mathrm{N}, 1^{\circ} 10^{\prime} \mathrm{W}$ & & $\mathrm{E}$ & $Q$. robur, $Q$. ilex & $\begin{array}{l}\text { Cytisus scoparius, Q. ilex, Cistus salvifolius, } \\
\text { Q. robur }\end{array}$ \\
\hline \multirow{2}{*}{$\begin{array}{l}\text { Biscarrosse 1 } \\
\text { (Bisc.1) }\end{array}$} & Forest & $44^{\circ} 26^{\prime} \mathrm{N}, 1^{\circ} 13^{\prime} \mathrm{W}$ & 102 & $\mathrm{E}$ & Q. robur & Ilex aquifolium, Arbutus unedo, $Q$. robur \\
\hline & Gap & $44^{\circ} 01^{\prime} \mathrm{N}, 1^{\circ} 12^{\prime} \mathrm{W}$ & & $\mathrm{E}$ & Q. robur & Arbutus unedo, $Q$. robur \\
\hline \multirow{2}{*}{$\begin{array}{c}\text { Biscarrosse } 2 \\
\text { (Bisc. } 2)\end{array}$} & Forest & $44^{\circ} 27^{\prime} \mathrm{N}, 1^{\circ} 13^{\prime} \mathrm{W}$ & 103 & $\mathrm{~W}$ & Q. robur & Cytisus scoparius, Arbutus unedo \\
\hline & Gap & $44^{\circ} 26^{\prime} \mathrm{N}, 1^{\circ} 12^{\prime} \mathrm{W}$ & & $\mathrm{W}$ & Q. robur & $\begin{array}{l}\text { Arbutus unedo, Cistus salvifolius, Cytisus } \\
\text { scoparius, Ulex europaeus, Q. robur }\end{array}$ \\
\hline \multirow[t]{2}{*}{ Born (Bo.) } & Forest & $44^{\circ} 02^{\prime} \mathrm{N}, 1^{\circ} 17^{\prime} \mathrm{W}$ & 222 & $\mathrm{E}$ & Q. robur, Q. suber & Erica cinerea, Ulex europaeus, $Q$. robur \\
\hline & Gap & $44^{\circ} 01^{\prime} \mathrm{N}, 1^{\circ} 17^{\prime} \mathrm{W}$ & & $\mathrm{E}$ & Q. robur, Q. suber & Cytisus scoparius \\
\hline \multirow[t]{2}{*}{ Seignosse (Se.) } & Forest & $43^{\circ} 41^{\prime} \mathrm{N}, 1^{\circ} 25^{\prime} \mathrm{W}$ & 240 & $\mathrm{E}$ & Q. robur, Q. suber & $\begin{array}{l}\text { Arbutus unedo, Ilex aquifolium, Ruscus } \\
\text { aculeatus }\end{array}$ \\
\hline & Gap & $43^{\circ} 41^{\prime} \mathrm{N}, 1^{\circ} 24^{\prime} \mathrm{W}$ & & $\mathrm{E}$ & Q. robur, Q. suber & $\begin{array}{l}\text { Erica cinerea, Calluna vulgaris, Ruscus } \\
\text { aculeatus, Q. suber }\end{array}$ \\
\hline
\end{tabular}

seedlings) and the adult trees were excluded from the data set. The Cartesian coordinates $( \pm 1 \mathrm{~cm})$ of all individuals of woody plants inside a plot were recorded by using metric tapes along the longer ( $x$-axis, $21 \mathrm{~m})$ and shorter $(y$-axis, $15 \mathrm{~m}$ ) sides of the plot. Additional tapes were placed every $3 \mathrm{~m}$ (35 quadrats of $9 \mathrm{~m}^{2}$ ) to measure the coordinates of the center of the main stem of each tree individual relatively to the reference point $(x, y)=(0.0)$ of the plot, located in its lower right corner. The total number of mapped individuals was 5,731 with 4,514 oak seedlings and 1,217 shrubs individuals with average of canopy area $223 \mathrm{~cm}^{2}$.

Associational spatial patterns of oak seedlings with their shrub neighbors were analyzed using the pair correlation function (Wiegand and Moloney 2004). This function is useful for analyzing the second-order properties of fully mapped spatial point patterns within increasing distance scales. Compared to the more commonly used Ripley's $K$ function in point pattern data analysis, the pair correlation function has the advantage of being noncumulative, where spatial patterns at finer scales does not influence the function at broader scales. Moreover, the pair correlation function tests for interactions between points separated by a distance $r$, whereas the cumulative $K$ function confounds effects at larger scales with effects at finer scales and refers to interactions within a distance $r$ (Getis and Franklin 1987).

Since we aimed at studying spatial associations between two point patterns (shrubs, pattern 1; oak seedlings, pattern 2 ) at different spatial scales, we used the bivariate version of the pair correlation function. Mathematically, the pair correlation function is the normalized density of neighboring pattern 2 points (i.e., the density of pattern 2 points at the plot scale) as a function of distance $r$ from average pattern 1 points; (Wiegand and Moloney 2004). It is defined as:

$g_{12}(r)=\frac{\sum_{i=1}^{n_{1}} P_{2}\left[R_{i}^{w}(r)\right]}{\sum_{i=1}^{n_{1}} A\left[R_{i}^{w}(r)\right]} / \lambda_{2}$

Where $n_{1}$ is the number of points of pattern $1, R_{i}^{w}(r)$ is the ring with radius $r$ and width $w=0.5 \mathrm{~m}$ centered around the $i$ th point of pattern $1, P_{2}$ is the number of points of pattern 2 within $R_{i}^{w}(r), A$ is the area of the ring, and $\lambda_{2}$ is the intensity of point pattern 2 . When, $g_{12}(r)>1$, seedlings display attraction to shrubs (i.e., positive association). When $g_{12}(r)<1$, seedlings exhibit repulsion from shrubs (i.e., negative association). When $g_{12}(r)=1$, seedlings and shrubs are independent. Within each plot, we computed the bivariate pair correlation function considering radii ranging from 0.25 to $3 \mathrm{~m}$, with intervals of $0.25 \mathrm{~m}$.

Since shrubs species composition naturally varies across plots, we pooled the shrubs in each plot. In order to detect possible interspecific positive or negative associations between oak seedlings and pooled shrubs at increasing distances, we compared our data to the antecedent conditions null model to test whether during the establishment the pattern of oak seedlings is influenced by the pattern of shrubs. For that purpose, the locations of the oak seedlings were randomized and shrub locations were maintained fixed (assuming that oak seedlings may occur anywhere in the plot and that the shrub pattern did not change during the development of seedlings; Wiegand and Moloney 2004). To 
test the significance of patterns against the null model, approximate (two sided) $95 \%$ simulation envelopes were generated by calculating for each distance $r$ of the fifth lowest and highest values using 99 Monte Carlo simulations of the null model; this yields an approximate $5 \%$ error rate. We performed goodness-of-fit tests in order to avoid the risk of inflating type I errors due to the simultaneous testing of the null hypothesis at several spatial scales (Diggle 2003). We used the Programita software for all point pattern analyses (Wiegand and Moloney 2004).

\section{Effects of summer drought and canopy opening on the strength of the oak seedling-shrub spatial association}

In order to test if associational patterns of oak seedlings with pooled understory shrubs were influenced by the climate drought and canopy opening, we calculated at each site an index of association strength (IA; Fajardo et al. 2006).

$\mathrm{IA}(\mathrm{r})=\frac{\mathrm{g}_{12}(\mathrm{r})-1}{|\mathrm{CE}-1|}$

This index $\operatorname{IA}(r)$ is a ratio between the observed value of $g_{12}(r)$ and the corresponding $y$ coordinate of the upper (if $g_{12}>1$ ) or lower (if $g_{12}<1$ ) confidence envelope at distance $r$. We calculated this index at three distances $(1,2$, and $3 \mathrm{~m})$, assuming that beyond $3 \mathrm{~m}$ the patterns are more influenced by environmental heterogeneity than by biotic interactions (Wiegand and Moloney 2004). In order to characterize the climate drought stress acting at each of our 10 plots, we calculated a Summer Moisture Index (SMI) derived from Lang (1920):

$\mathrm{SMI}=\frac{\mathrm{P}_{\text {summer }}}{\overline{\mathrm{T}}_{\max }}$

Where $P$ and $T$ representing the precipitation and the mean of maximum temperatures calculated for the three summer months (June, July, and August). This index decreases with increasing summer drought, from south to north in our study. The climate data used here were the average of the 1998-2008 period obtained from the nearest meteorological stations to the study sites (maximum distance from study plots $=16 \mathrm{~km}$ ) (Meteo-France data 2008).

Since the three oak species were not present naturally in each site, the three species were pooled. At each of the three studied distances, effects of summer drought and canopy opening treatments on IA values of shrub-oak seedlings associations were analyzed using quadratic analysis of covariance (ANCOVA) models including one factor (canopy treatment: forest or gap) and one covariate (summer drought represented by the SMI gradient). For each of the three distances taken into consideration, the ANCOVA model was summarized as follows:

$$
Y_{i j}=\mu+\alpha_{i}+\beta \mathrm{SMI}_{\mathrm{ij}}+\gamma_{\mathrm{i}} \mathrm{SMI}+\delta \mathrm{SMI}_{\mathrm{ij}}^{2}+\eta_{\mathrm{i}} \mathrm{SMI}_{\mathrm{ij}}^{2}+\varepsilon_{\mathrm{ij}}
$$

Where $Y_{\mathrm{ij}}$ is the IA measured on individual $j$ under canopy condition $i, \mu$ is the global mean of IA, $\alpha_{i}$ is the mean contribution of canopy condition $i$ to the mean of the IA index, $\beta$ is the mean slope, $\mathrm{SMI}_{\mathrm{ij}}$ is the summer moisture index undergone by individual $j$ under canopy condition $i, \gamma_{i}$ is the contribution of canopy condition $i$ to the slope, $\delta$ is the mean quadratic coefficient, $\eta_{i}$ is the contribution of canopy condition $i$ to the quadratic term, and $\varepsilon_{i j}$ is the residual error. Normality and homoscedasticity of residuals assumptions were met in all models. All analyses were performed using the $\mathrm{R}$ software for statistical computing (version 2.10.1, 2010).

\section{Results}

Overall, the spatial pattern analysis revealed dominant significant positive associations in the two northern sites (Soulac and Hourtin) and dominant significant negative associations in the southernmost site (Seignosse), whereas most spatial patterns were not significantly different from the null hypothesis in the center of Aquitaine (Biscarrosse) and in the other southern site (Born, Table 2). More precisely in the north, and for both $Q$. robur and $Q$. ilex seedlings, the spatial associations were positive at all distances in the gap plot (Ho.G), but only at small distances in the forest plot (So.F), with even independent associations occurring up to a distance of $3 \mathrm{~m}$ (Table 2; Figs. 1a and b). In the southernmost site, where both $Q$. robur and $Q$. suber seedlings were present, spatial associations for both species were significantly negative at all distances in the forest (Se.F) but only at small distances in the gap (Se.G), with even positive associations occurring at a distance of $2 \mathrm{~m}$ distance for Q. robur (Table 2; Figs. 1g and h). Finally, in the center (Born and Biscarrosse sites), six cases among eight were not significant and the two significant cases observed in gaps for $Q$. robur were quite complex to understand; at small distances, there were positive associations in the Born site and negative associations in the Biscarrosse 1 site but these patterns turn to independent up to a distance of $3 \mathrm{~m}$ (Table 2; Figs.1d and f).

The index of the association strength was significantly affected by the summer drought of the sites at the three analyzed distances (from 1 to $3 \mathrm{~m} ; P=0.03,0.02$, and 0.03 , respectively), with a shift from positive values in the dry north to negative values in the wet south (Table 3; Fig. 2). There was also a significant effect of the canopy treatment, but only at distances of 2 and $3 \mathrm{~m}(P=0.03$ and 0.03 , respectively; Table 3; Fig. 2). Furthermore, there was a 
Table 2 Signs of the spatial associational patterns between oak seedlings and interspecific shrubs based on bivariate $g_{12}(r)$ function for the 10 plots

\begin{tabular}{|c|c|c|c|c|c|c|c|c|c|c|c|c|c|c|c|}
\hline \multirow[t]{2}{*}{ Site } & \multirow[t]{2}{*}{ Target oak species } & \multirow[t]{2}{*}{$n 1 / n 2$} & \multicolumn{12}{|c|}{ Distance $t(\mathrm{~m})$} & \multirow[b]{2}{*}{$P$} \\
\hline & & & 0.25 & 0.5 & 0.75 & 1 & 1.25 & 1.5 & 1.75 & 2 & 2.25 & 2.5 & 2.75 & 3 & \\
\hline \multirow[t]{2}{*}{ So.F } & Q. robur & $155 / 34$ & & & + & + & & & & & & & & & 0.01 \\
\hline & Q. ilex & $47 / 1067$ & & & + & + & + & + & + & & & & & & 0.02 \\
\hline \multirow[t]{2}{*}{ Ho.G } & Q. robur & $122 / 147$ & + & + & + & + & + & + & + & + & + & + & + & + & 0.01 \\
\hline & Q. ilex & $85 / 192$ & + & + & + & + & + & + & + & + & + & + & + & + & 0.01 \\
\hline Bis.1F & Q. robur & $130 / 198$ & & & & + & & & & & & & & & 0.4 \\
\hline Bis.1G & Q. robur & $53 / 134$ & - & - & & - & - & & & & & & & & 0.01 \\
\hline Bis. $2 \mathrm{~F}$ & Q. robur & $162 / 41$ & & & & & & & & & & & & & 0.69 \\
\hline Bis. $2 \mathrm{G}$ & Q. robur & $134 / 80$ & - & - & & & & & & & & & & & 0.06 \\
\hline \multirow[t]{2}{*}{ Bo.F } & Q. robur & $48 / 63$ & & & & & & & - & & & & & & 0.34 \\
\hline & Q. suber & $101 / 66$ & - & & & - & & & & & & & & & 0.15 \\
\hline \multirow[t]{2}{*}{ Bo.G } & Q. robur & $83 / 92$ & + & + & + & & & & & & & & - & - & 0.01 \\
\hline & Q. suber & $96 / 58$ & & & & & & & & & & & & & 0.7 \\
\hline \multirow[t]{2}{*}{ Se.F } & Q. robur & $107 / 58$ & - & - & & - & - & - & - & - & - & - & - & - & 0.01 \\
\hline & Q. suber & $107 / 627$ & - & - & - & - & - & - & - & - & - & - & - & - & 0.01 \\
\hline \multirow[t]{2}{*}{ Se.G } & Q. robur & $127 / 735$ & & & - & - & - & & & & + & + & + & + & 0.01 \\
\hline & Q. suber & $114 / 922$ & - & - & & - & & & & & & & & & 0.04 \\
\hline
\end{tabular}

+ Significant positive association, - significance negative association, no symbol indicates no significant association. $F$ and $G$ are forest and gap plots, respectively; $n 1$ and $n 2$ correspond to the number of shrubs and of target oak species, respectively. See Table 1 for site abbreviations

$P$ value computed through goodness-of-fit test used for overall significance of patterns over the complete range of $t$

significant interaction between the summer drought and canopy treatments $(P=0.05,0.03$, and 0.03 , respectively) due to the occurrence of significant effects of the canopy treatment only at the driest and wettest ends of the summer drought gradient, but not at intermediate position (Table 3; Fig. 2). Finally, the occurrence of significant quadratic interaction terms at all distances shows that the IA curve switches from convex to concave when passing from the forest to the gap (Table 3; Fig. 2). Considering the summer moisture index interval of this study (see Fig. 2), this means that the IA reached zero asymptotically at the wet end of the gradient in gaps, whereas its decrease towards negative values was accelerated along the drought gradient under forest canopies.

Species effects could not be tested statistically since all species were not present in each site. However, there were graphically no obvious differences in species responses within sites, i.e., between $Q$. robur and $Q$. ilex at the two northern sites and between $Q$. robur and $Q$. suber at the two southern sites (Fig. 2).

\section{Discussion}

In agreement with our two first hypotheses, both summer drought and canopy removal increased positive associations between oak regeneration and understory shrubs in the coastal sand dune forest communities of the Aquitaine region. Although our design did not allow us to fully assess the species effect in our study, no obvious differences in species responses were recorded within sites (i.e., between Q. robur and $Q$. ilex at the two northern sites and between $Q$. robur and $Q$. suber at the two southern sites (Fig. 2), which shows at least that the response of the deciduous $Q$. robur did not differ from that of the two evergreen species.

\section{Positive associations increase with summer drought and canopy opening}

Our results showed that positive spatial associations between oak seedlings and understory shrubs significantly dominated in the dry climate of the north of Aquitaine and spatial negative associations were more frequent in the wet climate of the south of Aquitaine. Additionally, canopy openings increased the positive effect of the shrubs in the dry north but decreased negative effects of shrubs in the wet south toward independent or positive association pattern. These results support the SGH (Bertness and Callaway 1994) arguing that positive effects of woody or herbaceous species on tree seedlings or saplings are more frequent in open forests or woodland communities from severe environments than in closed forests from benign climate conditions (Callaway et al. 1996; Rodriguez-Garcia et al. 2011a; 
Fig. 1 The interspecific association patterns of shrub $Q$. robur seedling up to $3 \mathrm{~m}$ scale along $240 \mathrm{~km}$ climate gradient. The blue dotted line represents the observed pair correlation values $g_{12}(r)$. The red lines represent the confidence envelope constructed by using the fifth heights and fifth lowest value of 99 Monte Carlo simulations of the null model. Values above and below the envelope indicate significant positive and negative associations, respectively. See Table 1 for site abbreviations
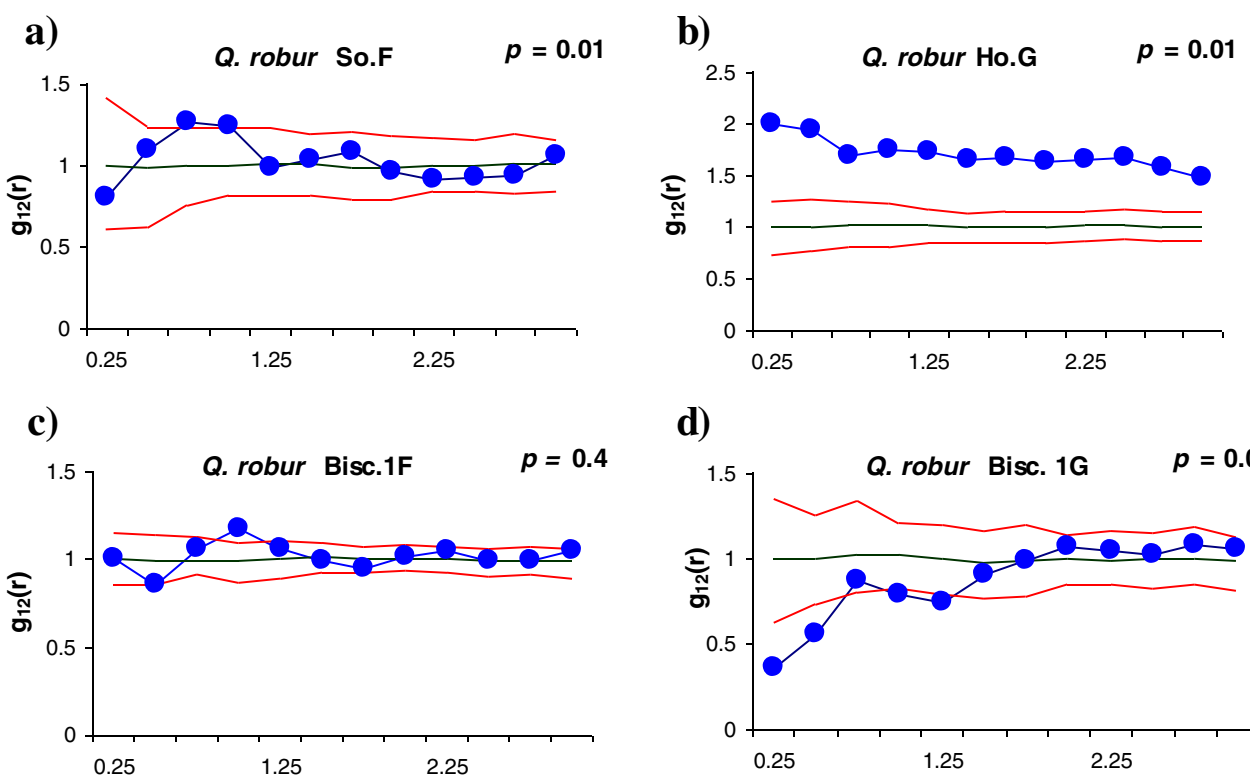

d)

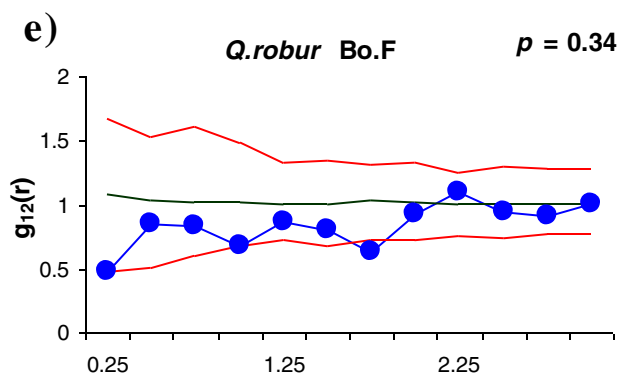

g)

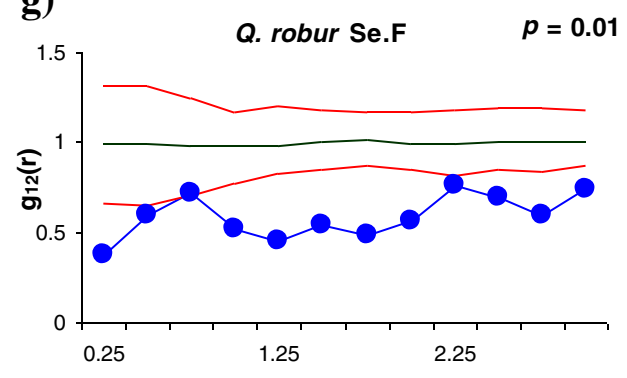

Distance (m)

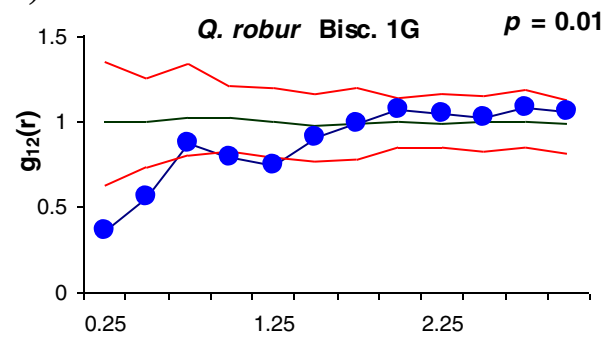

f )

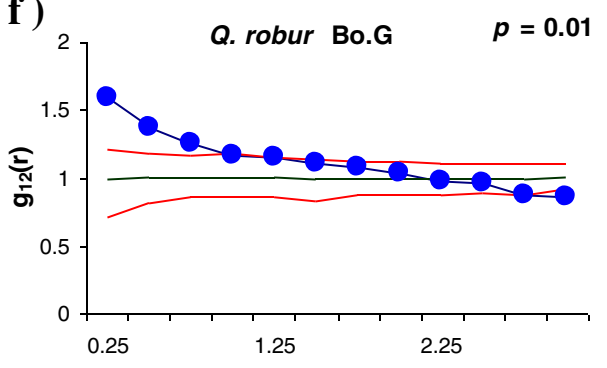

h)

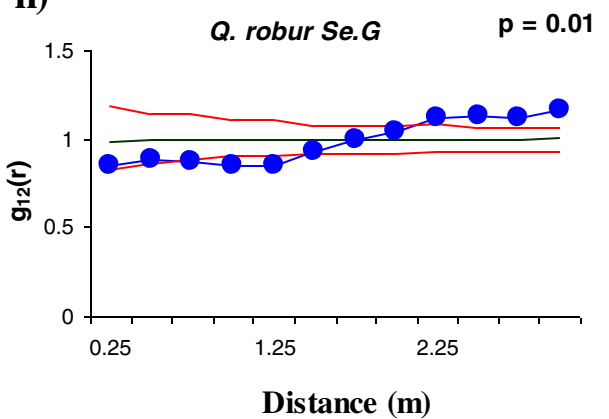

Saccone et al. 2009). However, it has also been shown that both facilitation and competition may occur through time in a single site (Fotelli et al. 2001) but that the net balance depends on the species and the ecological factor involved in the interaction (Gomez-Aparicio 2009; Michalet 2007; Saccone et al. 2009; Pugnaire and Luque 2001). Specifically, Michalet (2007) proposed that facilitation should rather involve nonresource factors (such as decrease in vapor pressure deficit, extreme temperatures, and photoinhibition), whereas competition is more likely to occur when the limiting factors are resources (such as water or nutrient availability). For example, Saccone et al. (2009) showed during the $2003 \mathrm{Eu}-$ ropean heat wave in a single system that the forest canopy facilitated seedlings of Abies alba through atmospheric stress mitigation but that adult trees competed for water with the seedlings of Picea abies. Although we did not measure environmental conditions in our study, it is very likely that the positive effects of understory shrubs in the dry north of Aquitaine were not due to decrease in soil water stress in these sandy soil conditions but rather to decrease in irradiance, vapor pressure deficit, and extreme temperatures. Indeed, in the north, positive associations with shrubs were much stronger in the gaps than in the forests, likely because oak seedlings were protected from atmospheric stress by the tree canopy in the forests but not in the gaps. Additionally, all neighbors in our study were shrubs, known to provide strong aboveground 
Table 3 Results of ANCOVAs tests for the effects of summer drought, canopy opening, and their interaction on the index of association strength at distances of 1,2 , and $3 \mathrm{~m}$

\begin{tabular}{|c|c|c|c|c|c|c|}
\hline \multirow[t]{2}{*}{ Treatments } & \multicolumn{6}{|c|}{ Distances } \\
\hline & $F$ & $\begin{array}{l}1 \mathrm{~m} \\
P\end{array}$ & $F$ & $\begin{array}{l}2 \mathrm{~m} \\
P\end{array}$ & $F$ & $\begin{array}{l}3 \mathrm{~m} \\
P\end{array}$ \\
\hline Canopy & 4.934 & 0.052 & 6.690 & 0.027 & 6.772 & 0.026 \\
\hline Summer moisture & 6.787 & 0.026 & 9.109 & 0.012 & 5.875 & 0.035 \\
\hline Summer moisture $^{2}$ & 7.612 & 0.020 & 9.947 & 0.010 & 6.333 & 0.030 \\
\hline Canopy $\times$ summer moisture & 4.921 & 0.050 & 6.716 & 0.026 & 6.671 & 0.027 \\
\hline Canopy $\times$ summer moisture ${ }^{2}$ & 4.982 & 0.049 & 6.886 & 0.025 & 6.708 & 0.026 \\
\hline
\end{tabular}

positive effects and low belowground negative effects, as compared to grasses (Castro et al. 2004; Gomez-Aparicio 2009; Michalet 2007). However, in the gaps of the dry north, positive associations may also be due to indirect facilitative effects of shrubs, i.e., grass competition release (Callaway 2007; Cuesta et al. 2010).

We are aware that only a removal study may allow us to conclude on the real occurrence of shrub-oak seedling interactions in our study. However, our results are very unlikely to have been influenced by differences in soils between shrubs and open areas since our observations showed that the sandy soils were, at least for important physical characters such as soil depth and texture, very similar between both patches. The occurrence of important differences in soils depth between patches within communities is indeed more common in arid and semi-arid rocky areas than in sandy oceanic communities as those of our study, due to the importance of soil erosion processes in the former (Michalet 2006). Thus, our analysis of spatial patterns instead of real plant interactions was likely sufficient to suggest the long-term net balance of interactions in the system under study (Callaway and Walker 1997). Such information is certainly of higher value for managing tree regeneration than short-term removal studies.

\section{Spatial patterns were not influenced by target species functional strategies}

We were not able with our design to assess the difference in response between the two evergreen oaks since they naturally occur in different climate conditions. However, our design allowed us to assess differences in responses to the shrubs between $Q$. robur and $Q$. ilex or $Q$. suber at the northern and southern sites, respectively. Since temperate deciduous oaks, and in particular $Q$. robur, are known to be less tolerant to drought stress than evergreen Mediterranean oaks (Ozenda 1985), we hypothesized that the former will be more demanding of environmental amelioration by neighbors than the latter. Indeed, a number of authors have shown that drought-intolerant species are better candidates for facilitation than drought-tolerant ones since the benefit of having neighbors mitigating drought stress is higher for the former than for the latter (Liancourt et al. 2005; Michalet 2007; Saccone et al. 2009). Additionally, since there is a tradeoff between drought and shade tolerance in particular for tree species (Smith and Huston 1989), the addition of shade by neighbors is inducing a higher cost for a droughttolerant species than for a drought-intolerant one.

If, however, most of the facilitative effect of understory shrubs is not improvement in soil water availability but rather a mitigation of atmospheric stress and photoinhibition through decreasing irradiance as stressed above, then our three species may not differ enough in their atmospheric and light requirements to produce contrasting patterns of association with shrubs. Indeed, the three species do not have contrasting light requirements since both evergreen species are late successional species in a sunny Mediterranean context, i.e., avoiding atmospheric stress in full light conditions (Cuesta et al. 2010; Penuelas et al. 2001; Perez-Devesa et al. 2008), whereas $Q$. robur is rather considered as a postpioneer species, requiring gaps for regeneration in a shady temperate context (Cater and Batic 2006; Rozas 2003).

\section{Conclusions}

Our study showed that spatial patterns of association between understory shrubs and oak seedlings are very sensitive to increasing drought and canopy opening independent of the oak species. Climate change models predict a strong decrease in summer rainfall in the Aquitaine region with a shift from a current warm temperate climate toward a submediterranean climate at the end of the century. Our results suggest that with climate change, the positive effect of understory shrubs on tree seedlings should increase in the forest gaps of the north of Aquitaine. Thus, in a perspective of climate change-adapted management, foresters should rather conserve understory nurses in gaps in order to limit oak seedlings mortality due to drought and extreme 
Fig. 2 Regressions of the IA calculated at three distances (1, 2 , and $3 \mathrm{~m}$ ) against the SMI for the 10 plots and the three target oak species. The full and empty circles represent the forest and gap plots, respectively, whereas the blue, red, and green circles represent $Q$. robur, $Q$. suber, and $Q$. ilex targets, respectively. The full line represents the regression for the forest plots, whereas the dashed line represents the regression for the gap plots. The two dashed red lines represent the confidence envelope area around the expected 0 value of $g_{12}(r)$. See Table 1 for site abbreviations
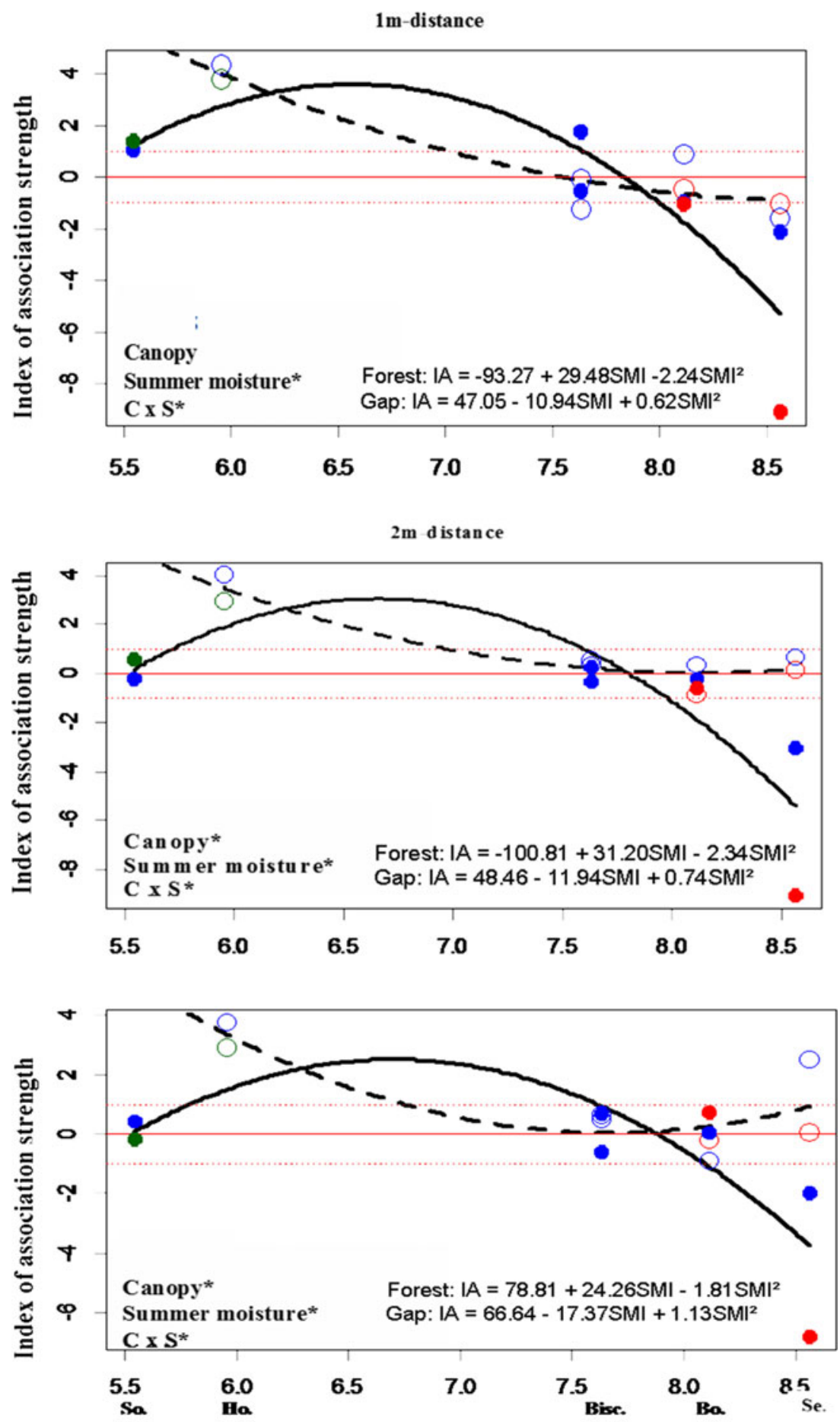

Summer moisture index irradiance. However, we are aware that measuring seedling performance parameters in relation to presence and absence of the shrubs may further support our observational results of this study. Therefore, experiments including transplantations of the three species all along the gradient are currently being conducted in this system. Such design will allow us to also more straightforwardly test the role of target species functional strategy since all oak species do not occur in all climate conditions. Additionally, environmental measurements (light, soil moisture, and VPD) should be conducted in order to analyze the relative roles of atmospheric vs. soil water stress in driving changes in biotic interactions between understory shrubs and oak seedlings along complex environmental gradients. 
Acknowledgments We thank Fabien Rizinjirabake and Chantal Hélou for assistance in the field. We are grateful to the "Office national de Foret" (O.N.F.) and in particularly Didier Canteloup for permission to work in coastal sand dune forests. We would like to thank the anonymous reviewers for their helpful suggestions and comments. The first author received a scholarship from EU through Erasmus Mundus program Lot 10

\section{References}

Balandier P, Collet C, Miller JH, Reynolds PE, Zedaker SM (2006) Designing forest vegetation management strategies based on the mechanisms and dynamics of crop tree competition by neighbouring vegetation. Forestry 79:3-27

Bertness MD, Callaway R (1994) Positive interactions in communities. Trends in Ecol Evol 9:191-193. doi:10.1016/0169-5347 (94)90088-4

Brooker RW (2006) Plant-plant interactions and environmental change. New Phytol 171:271-284. doi:10.1111/j.14698137.2006.01752.x

Brooker RW (2010) Plant communities, plant-plant interactions, and climate change. In: Pugnaire FI (ed) Positive plant interactions and community dynamics. CRC Press, Boca Raton, FL, pp 99123

Callaway RM (2007) Positive interactions and interdependence in plant communities. Springer, Dordrecht, The Netherlands

Callaway RM, DeLucia EH, Moore D, Nowak R, Schlesinger WH (1996) Competition and facilitation: contrasting effects of Artemisia tridentata on desert vs. montane pines. Ecology 77:2130 2141. doi: $10.2307 / 2265707$

Callaway RM, Walker LR (1997) Competition and facilitation: a synthetic approach to interactions in plant communities. Ecology 78:1958-1965. doi:10.1890/0012-9658(1997)078\%5B1958: cafasa\%5D2.0.co;2

Castro J, Zamora R, Hodar JA, Gomez JM, Gomez-Aparicio L (2004) Benefits of using shrubs as nurse plants for reforestation in Mediterranean mountains: a 4-year study. Restor Ecol 12:352358. doi:10.1111/j.1061-2971.2004.0316.x

Cater M, Batic F (2006) Groundwater and light conditions as factors in the survival of pedunculate oak (Quercus robur L.) seedlings. Eur J For Res 125:419-426. doi:10.1007/s10342-006-0134-6

Cuesta B, Villar-Salvador P, Puertolas J, Benayas JMR, Michalet R (2010) Facilitation of Quercus ilex in Mediterranean shrubland is explained by both direct and indirect interactions mediated by herbs. J Ecol 98:687-696. doi:10.1111/j.1365-2745.2010.01655.x

David TS, Henriques MO, Kurz-Besson C, Nunes J, Valente F, Vaz M, Pereira JS, Siegwolf R, Chaves MM, Gazarini LC, David JS (2007) Water-use strategies in two co-occurring Mediterranean evergreen oaks: surviving the summer drought. Tree Physiol 27:793-803

Diggle PJ (2003) Statistical analysis of spatial point patterns, 2nd edn. Oxford University Press, New York. ISBN 0-340-74070-1

Fajardo A, Goodburn JM, Graham J (2006) Spatial patterns of regeneration in managed uneven-aged ponderosa pine Douglas-fir forests of Western Montana USA. Forest For Ecol Manage 223:255266. doi:10.1016/j.foreco.2005.11.022

Fotelli MN, Gessler A, Peuke AD, Rennenberg H (2001) Drought affects the competitive interactions between Fagus sylvatica seedlings and an early successional species, Rubus fruticosus: responses of growth, water status and delta $13 \mathrm{C}$ composition. New Phytol 151:427-435. doi:10.1046/j.1469-8137.2001.00186.x

Getis A, Franklin J (1987) Second-order neighborhood analysis of mapped point patterns. Ecology 68:473-477
Gomez-Aparicio L (2009) The role of plant interactions in the restoration of degraded ecosystems: a meta-analysis across life-forms and ecosystems. J Ecol 97:1202-1214. doi:10.1111/j.1365-2745.2009.01573.x

Gomez-Aparicio L, Zamora R, Gomez JM, Hodar JA, Castro J, Baraza E (2004) Applying plant facilitation to forest restoration: a metaanalysis of the use of shrubs as nurse plants. Ecol Applica $14: 1128-1138$

Intergovernmental Panel on Climate Change (2007) Climate change 2007: impacts, adaptation and vulnerability. Contribution of Working Group II to the 4th Assessment Report of the Intergovernmental Panel on Climate Change. Cambridge University Press, Cambridge, UK

Lang R (1920) Verwitterung und Bodenbildung als Einführung in die Boden-Kunde. Stutgart, Deutschland (quoted by Thornthwaite C.W, Holzman B (1942) Measurement of evaporation from land and water surfaces. USDA Tech Bull 817:1-143

Law R, Illian J, Burslem D, Gratzer G, Gunatilleke CVS, Gunatilleke I (2009) Ecological information from spatial patterns of plants: insights from point process theory. J Ecol 97:616-628. doi:10.1111/j.1365-2745.2009.01510.x

Liancourt P, Callaway RM, Michalet R (2005) Stress tolerance and competitive-response ability determine the outcome of biotic interactions. Ecology 86:1611-1618. doi:10.1890/04-1398

McIntire EJB, Fajardo A (2009) Beyond description: the active and effective way to infer processes from spatial patterns. Ecology 90:46-56. doi:10.1890/07-2096.1

Mendoza I, Zamora R, Castro J (2009) A seeding experiment for testing treecommunity recruitment under variable environments: implications for forest regeneration and conservation in Mediterranean habitats. Biol Conserv 142:1491-1499. doi:10.1016/j.biocon.2009.02.018

Meyer KM, Ward D, Wiegand K, Moustakas A (2008) Multi-proxy evidence for competition between savanna woody species. Perspect Plant Ecol Evol Syst 10:63-72

Michalet R, (1991) Une approche synthétique bio pédoclimatique des montagnes méditerranéennes: exemple du Maroc septentrional. Thèse Doct., Univ. Joseph Fourier, Grenoble I, France.

Michalet R (2006) Is facilitation in arid environments the result of direct or complex interactions. New Phytol 169:3-6

Michalet R (2007) Highlighting the multiple drivers of change in interactions along stress gradients. New Phytol 173:3-6. doi:10.1111/j.1469-8137.2006.01949.x

Millar CI, Stephenson NL, Stephens SL (2007) Climate change and forests of the future: managing in the face of uncertainty. Ecol Appl 17:2145-2151. doi:10.1890/06-1715.1

Nambiar EKS, Sands R (1993) Competition for water and nutrients in forests. Canadian Can J For Res 23:1955-1968. doi:10.1139/x93-247

Nathan R, Muller-Landau HC (2000) Spatial patterns of seed dispersal, their determinants and consequences for recruitment. Trends Ecol Evol 15:278-285

Ozenda P (1985) La végétation de la chaîne alpine dans l'espace montagnard européen. Masson, Paris, France

Padilla FM, Pugnaire FI (2006) The role of nurse plants in the restoration of degraded environments. Front Ecol Envir 4:196-202. doi:10.1890/1540-9295(2006)004\%5B0196:tronpi\%5D2.0.co;2

Penuelas J, Lloret F, Montoya R (2001) Severe drought effects on Mediterranean woody flora in Spain. For Sci 47:214-218

Perez-Devesa M, Cortina J, Vilagrosa A, Vallejo R (2008) Shrubland management to promote Quercus suber L. establishment. For Ecol Manage 255:374-382. doi:10.1016/j.foreco.2007.09.74

Pugnaire FI, Luque MT (2001) Changes in plant interactions along a gradient of environmental stress. Oikos 93:42-49. doi:10.1034/ j.1600-0706.2001.930104.x

Rodriguez-Garcia E, Bravo F, Spies TA (2011a) Effects of overstorey canopy, plant-plant interactions and soil properties on Mediterranean maritime pine seedling dynamics. For Ecol Manage 262:244-251. doi:10.1016/j.foreco.2011.03.029 
Rodriguez-Garcia E, Ordonez C, Bravo F (2011b) Effects of shrub and canopy cover on the relative growth rate of Pinus pinaster Ait. seedlings of different sizes. Ann For Sci 68:337-346

Rozas V (2003) Regeneration patterns, dendroecology, and forest-use history in an old-growth beech-oak lowland forest in Northern Spain. For Ecol Manage 182:175-194. doi:10.1016/s0378-1127 (03)00070-7

Saccone P, Pages JP, Girel J, Brun JJ, Michalet R (2009) The role of biotic interactions in altering tree seedling responses to an extreme climatic event. J Veg Sci 20:403-414. doi:10.1111/j.16541103.2009.01012.x

Saccone P, Pages JP, Girel J, Brun JJ, Michalet R (2010) Acer negundo invasion along a successional gradient: early direct facilitation by native pioneers and late indirect facilitation by conspecifics. New Phytol 187:831-842. doi:10.1111/j.1469-8137.2010.03289.x
Smith T, Huston M (1989) A theory of the spatial and temporal dynamics of plant communities. Vegetatio 83:49-69. doi:10.1007/bf00031680

Steenberg JWN, Duinker PN, Bush PG (2011) Exploring adaptation to climate change in the forests of central Nova Scotia, Canada. For Ecol Manage 262:2316-2327. doi:10.1016/j.foreco.2011.08.027

Suarez ML, Kitzberger T (2008) Recruitment patterns following a severe drought: long-term compositional shifts in Patagonian forests. Can J For Res 38:3002-3010. doi:10.1139/x08-149

Wiegand T, Kissling WD, Cipriotti PA, Aguiar MR (2006) Extending point pattern analysis for objects of finite size and irregular shape. J Ecol 94:825-837. doi:10.1111/j.1365-2745.2006.01113.x

Wiegand T, Moloney KA (2004) Rings, circles, and null-models for point pattern analysis in ecology. Oikos 104:209-229. doi:10.1111/j.0030-1299.2004.12497.x 